\title{
CARACTERIZACIÓN QUÍMICA DEL PERMEADO DE SUERO COMO ABONO. VARIACIÓN ESTACIONAL Y POR PROCEDENCIA
}

\author{
Felli, O. M. ${ }^{1}$; Badino, O. ${ }^{1}$; Pilatti, M. A. ${ }^{1}$ \& Alesso, C. A. ${ }^{1}$
}

\begin{abstract}
RESUMEN
El permeado de suero (PS) es un subproducto de la elaboración de quesos y de la extracción de concentrados proteicos del suero. Contiene lactosa y sales minerales, posibles nutrientes para los cultivos que puede utilizarse como complemento de la fertilización. El objetivo del trabajo fue evaluar el efecto de los diferentes meses del año sobre parámetros químicos y físicoquímicos del PS en dos procesadoras lácteas ubicadas en la Región Centro de Argentina. Se analizaron: $\mathrm{pH}$, conductividad eléctrica $(\mathrm{CE})$, sólidos totales $(\mathrm{ST})$, nitrógeno $(\mathrm{Nt})$, fósforo total $(\mathrm{Pt})$, potasio $(\mathrm{K})$, sulfatos (SO4), calcio $(\mathrm{Ca})$, magnesio $(\mathrm{Mg})$, cloruros $(\mathrm{Cl})$, sodio $(\mathrm{Na})$ y metales pesados. No se obtuvieron diferencias significativas en los parámetros analizados en cada planta láctea a través del año; sin embargo, se observaron diferencias entre plantas procesadoras para: $\mathrm{pH} ; \mathrm{CE} ; \mathrm{Pt} ; \mathrm{Na} ; \mathrm{Cl} ; \mathrm{Ca}$ y $\mathrm{Mg}$. No se detectaron metales pesados. Como nutrimento, el aporte más importante lo constituyen el $\mathrm{K}$, Ca y P y en menor medida el N, S y Mg. El contenido de sodio, cloruros, así como también de salinidad son elevados, motivo por el cual resulta conveniente evaluar su posible uso directo en el suelo tomando decisión sobre su monitoreo periódico. La comparación de contenidos del PS, entre países, presenta diferencias.

Palabras claves: permeado de suero, composición química, nutrimentos, abono suelos.
\end{abstract}

\section{SUMMARY}

\section{Chemical characterization of whey permeate as fertilizer. Seasonal varia- tion and by origin.}

A by product of the cheese production and the extraction of whey protein concentrates is the whey permeate (WP). It contains lactose and mineral salts, potential crop nutrients that can be used to supplement fertilization. The aim of this work was to evaluate the effect of the different months over chemical and physicalchemical parameters of WP, from two dairy processors located in the Central Region of Argentina. Were analyzed: $\mathrm{pH}$, conductivity (CE), total solids (TS), nitrogen (Nt),

* CAI+D 2009. 12/ C 117

1.- Facultad de Ciencias Agrarias (UNL). Kreder 2805. (3080) Esperanza, provincia de Santa Fe. Email: obadino@fca.unl.edu.ar

Manuscrito recibido el 14 de junio de 2012 y aceptado para su publicación el 15 de febrero de 2013. 
total phosphorus $(\mathrm{Pt})$, potassium $(\mathrm{K})$, sulfate ( $\mathrm{SO} 4)$, calcium $(\mathrm{Ca})$, magnesium $(\mathrm{Mg})$, chlorides $(\mathrm{Cl})$, sodium $(\mathrm{Na})$ and heavy metals. There were no significant differences in the parameters analyzed in each dairy plant throughout the year, however, there were differences between processing plants for: $\mathrm{pH}, \mathrm{CE}, \mathrm{Pt}, \mathrm{Na}, \mathrm{Cl}, \mathrm{Ca}$ and $\mathrm{Mg}$. No heavy metals were detected. As a nutrient, the most important contribution are the $\mathrm{K}, \mathrm{Ca}$ and $\mathrm{P}$ and to a lesser extent the $\mathrm{N}, \mathrm{S}$ and $\mathrm{Mg}$. The sodium, chlorides, as well as the salinity is high, to assess their potential. Therefore, it is desirable to use directly on the ground, making decisions with periodic monitoring. The contents of WP differs between countries.

Key words: whey permeate, chemical composition, nutrients, fertilizer.

\section{INTRODUCCIÓN}

Las tendencias de las actuales innovaciones tecnológicas provocan que los subproductos se reutilicen en otros procesos productivos, dándoles valor agregado y evitando desperdicios que puedan ocacionar problemas de contaminación ambiental (Giufré, 2003).

Un subproducto abundante de la industria láctea es el permeado de suero (PS) que se obtiene como remanente en procesos de ultrafiltración del suero para la producción de concentrados con alto contenido proteico denominado whey proteins concentrate, (WPC), los cuales contienen entre el 35 al 80\% de proteína (Pavel, 1979; González, 1996; Grasselli, 1997; Faría, 2003; Shaller, 2008).

El PS es rico en lactosa y sales minerales (Grasselli et al., 1997; Shaller, 2008) con lo cual podría aprovecharse como nutrimentos para los cultivos (Wendorff, 1989; Barnett, 2006), puesto que contiene nitrógeno $(\mathrm{N})$, fósforo $(\mathrm{P})$, potasio $(\mathrm{K})$, azufre $(\mathrm{S})$, calcio $(\mathrm{Ca})$, magnesio $(\mathrm{Mg})$, pudiendo complementar otras fuentes de fertilizantes. (Wendorff, 1989; Barnett \& Russell, 2006).

Los cultivos se fertilizan para suministrar los nutrimentos que no se hallan presentes en suficientes cantidades o accesibles en el suelo. De esta manera a través de la composición química de los fertilizantes más usados se puede considerar los efectos de cada nutrimento y la interacción entre los mismos. En el cuadro 1 se puede apreciar la composición química (grado) de algunos fertilizantes más usados en la región centro de Argentina. Si se determinan las dosis equivalentes en fertilizantes de cada uno de los componentes químicos del PS, se podría mejorar el diseño del programa de fertilización para optimizar sus efectos y evitar o disminuir consecuencias negativas al ambiente.

En Estados Unidos, Canadá y Nueva Zelanda se utiliza el PS en aplicaciones al suelo como fertilizante (Sharrat et al., 1959; Kelling et al., 1981; Wendorff, 1989, 1993; Bernard 1995, 2004; Rodenberg, 1998; Barnett et al., 2006; Ghaly et al., 2007). En Wisconsin (Estados Unidos) el 63\% de las procesadoras lácteas producen PS y el $43 \%$ se lo utiliza como abono de suelos (Wendorff, 2009). En cuanto a los contenidos de sodio $(\mathrm{Na})$, cloruros $(\mathrm{Cl})$, sales, olores y acidez, ello implicará el seguimiento, control y propuesta de remediación preventiva ya que podrían ocasionar daños a los cultivos y a las propiedades físicas, físico químicas y químicas del suelo, constituyéndose también en una potencial fuente de contaminación para agroecosistemas y acuíferos (Hort, 1974; Rail, 1989; Matzke et al.; 1993; Bernard, 1995, 2004).

En Canadá se utiliza también otro subproducto de la industria láctea en la fertilización del suelo: el Licor de Lactosuero (LLS) que es similar al PS; en el proceso de obtención 